\title{
The Feminist Politics of Naming Violence ${ }^{1}$
}

\section{Elizabeth Frazer, New College, Oxford, OX13BN elizabeth.frazer@new.ox.ac.uk Kimberly Hutchings, Queen Mary University of London, k.hutchings@qmul.ac.uk}

The naming of violence in feminist political campaigns and in the context of feminist theory has rhetorical and political effects. Feminist contention about the scope and meaning of 'violence against women' and 'sex and gender-based violence', and about the concepts of gender and of violence itself, are fundamentally debates about the politics of feminist contestation, and the goals, strategies and tactics of feminist organisation, campaigns, and action. This paper examines the propulsion since the late twentieth century of the problems of VAW and SGBV on to global and national political agendas. The feminist theory that underpins the uptake of this new agenda is contested by opponents of feminism. More significantly for the paper it is also contested within feminism, in disputes about how feminist political aims should be furthered, through what institutions, and with what strategic goals in view. The paper aims to show that theoretical and philosophical controversy about the concepts of violence, and sex and gender, are always political, both in the sense that they are an aspect of feminist competition about how feminist politics should proceed, and in the sense that the political implications of concepts and theory must always be a significant factor in their salience for feminist action.

Violence, Power, Political strategy, Feminism, Political theory, Violence against women, Gender, Sex and Gender Based Violence.

\footnotetext{
${ }^{1}$ Acknowledgements: An earlier version of this paper was presented at the Nuffield Political Theory Workshop, University of Oxford, 2018. We are grateful for comments and suggestions from Lucy Abbott and Katharine Millar; and to anonymous referees and the journal editors.
} 


\section{Introduction}

The aim of this paper is to examine internal tensions within the feminist politics of naming violence, in theory and policy contexts. Calling an action or its effects 'political violence' challenges and reframes established distinctions between what is and what is not violent, between what is and is not justifiable, and between what is and is not political. A major achievement of feminist theory and practice has been to transform conceptualisations of political violence, and thereby shift political understandings and agendas. Feminists have rejected naturalising, moralising, and criminalising discourses as inadequate to the phenomena they were seeking to address. Instead, they have named sexual and domestic violence against women an exercise of power, embedded in and reproducing patriarchal privilege and the subordination of women.

But the question of the meaning of 'violence' within feminist theory and practice remains contentious. This is particularly so in a context in which the concepts 'Violence against Women’ (VAW) and 'Sex and Gender-Based Violence’ (SGBV) have become prominent in national and international research and policy agendas. Where governments and international agencies (seek to) enforce policies and laws that are based on a specific understanding of social reality the stakes, for feminist theory and politics, are particularly high. In particular, for some feminist critics, theories of and policy reactions to 'violence against women' perversely endorse the binary hierarchy of sexual positions in which women are victims; while the related theoretical and policy notion of 'sex and gender based violence' is insufficient to grasp the way that gender, as a compulsory organising category, is itself a form of violence. We argue that debates between feminists about the definition of violence cannot be resolved in philosophical terms. They are, fundamentally, political contestations. Although parties to political contestation aim to achieve decisive definitions of states of 
affairs - that potentially can be encoded in law, and can be constitutive of new ways of life the outcomes of political contestation are also always (re)contestable. It is important that the irreducibly political nature of the concept and theory of violence is understood in feminism.

In what follows, we first examine examples of how theory and activism have transformed the meaning of violence, and some of the conceptual and political difficulties raised. We take the example of the translation of the work of feminist activism and theory into the domain of international public policy, and the development of the explicit international policy objective of eradication of VAW and SGBV, as a particularly significant instance of the politics of ongoing feminist work on violence. When a global authority like the United Nations adopts, promulgates, and acts on a specific account of gender relations and the nature and place of violence within them, that opens up rather than settles the question of the validity of that analysis.

\section{Feminist Namings and Re-Namings of Violence}

Feminists’ use of vocabularies of sex and gender violence imply that practices, from wife beating and female genital cutting to 'honour killings' and sexual violence in war, are prima facie political as well as wrong. Proponents and perpetrators of such violence have argued that it is natural or normal, or not violence at all - an expression of love, a punishment, or a moment of pathological excess. Alternatively, they rely on justifying the violence in terms of gendered norms. This contestation is clearly political, fought in part through the creation of new understandings of existing practices and new legitimacy criteria. In this section, we explore feminist conceptualisations of practices of gendered violence as political violence, and some of the debates this has provoked within feminist theory. 
Over the past fifty years, feminist analysis has emphasised the importance of grasping the implications of gendered violence from the standpoint of women experiencing it, or threatened by it (Kelly,1988; Brison, 1998; Lundgren,1998). This kind of phenomenological work opened up understanding of violence's controlling and destructive effects, beyond the specific physical damage inflicted. It drew attention to prevailing scepticism about women's testimony and consent, and to how police and judicial processes often amplified and repeated, rather than countered, the experience of such violence. Feminist work conceptualised violence expansively. This is evident in the idea of a continuum of violence, which links together experiences of threat, verbal abuse and physical attack, or at a broader level connects experiences of gendered violence across contexts of peace and war (Bryson, 1992; Davies, 1994; Bayard de Volo and Hall, 2015; Kelly,1988; Mackinnon, 2006). It is also evident in the role played by ideas such as structural, symbolic and epistemic violence in the relevant feminist contributions (Brunner, 2016; Dotson, 2011; Morgan and Björket, 2006; True, 2012).

Feminist work developed Galtung's (1975) concept of structural violence to refer to the system of patriarchal domination of men over women, masculine over feminine, that produces and legitimates gendered violence, and in which direct physical violence, or the threat of violence, is an element in the system of sexual and gender norms that reproduces women’s structural disadvantage. Brownmiller (1975) and Mackinnon (2006) see the prevalence of rape in warfare as demonstrating the ways in which sexual violence is not a matter of individual pathology but is integral to the systematic domination of women by men. Other kinds of violence against women, from genital cutting to the abortion of female foetuses to so-called 'honour' killings, are part of the same pattern (French, Teays \& Purdy, 1998; Dobash and Dobash, 1998; Hudson et al, 2012). 
Feminist work on structural violence points also to the importance of symbolic and epistemic violence (Spivak, 1988; Bourdieu, 2001; Brunner, 2016; Dotson, 2011). Such violence renders direct physical violence against women or feminised actors unremarkable or uninterpretable. In the context of VAW it includes the ways domestic and sexual violence are interpreted in terms of nature (sexual violence is a manifestation of biological drives), privilege (control over women is a matter of male entitlement) or desert (she asked for it). It also includes the host of everyday ways in which women and the feminine are denigrated and their victimisation thereby rendered simultaneously normal, so justified, and invisible (Morgan and Björket, 2006). Work on sexual violence in war has pointed to how symbolic and epistemic violences not only legitimise gendered violence, but are also mutually constitutive of it. Such violence affirms the identification of perpetrator with masculine superiority and victim with feminine inferiority, actively solidifying and reproducing nationalist and racialised hierarchies in the context of violent conflict (Skjelsbæk, 2003; Zarkov, 2001).

The foregrounding of women's experience and the stretching of the concept of violence to encompass structural and symbolic dimensions raises problems. Prominent amongst these are first, the question of how wide the boundaries of the concept of violence should be set. Some feminists argue that if too much is taken to fall under the category then it ceases to be either analytically or politically useful. Second, there is the question whether these ways of thinking essentialise and privilege women's experience, and treat women as an undifferentiated category. If this is so, forms of gendered violence directed not at women as such, but at trans or non-binary persons, or at homosexuals, for instance, and sometimes perpetrated by women, are rendered invisible. Third, the question whether predominant analyses of VAW naturalise and generalise women's position as one of fear and victimhood. This not only denies women agency but also implies that the answer to gendered violence 
must be state and legal protection at domestic and international levels (Brown,1995; Marcus,1992; Pratt and Richter-Devroe,2011; Shepherd,2008). Debates over these issues push feminist thinkers into unpacking a variety of conceptual and normative questions concerning what counts as violence, which in turn raises a series of questions both about how these phenomena are to be explained, and also what kinds of violence count as 'good' or 'bad' in feminist terms.

We can briefly illustrate these dynamics in relation to an example of feminist debate in the 1990s about the conceptual parameters and political implications of predominant feminist theories of domestic and sexual violence. Marcus (1992) and Brown (1995) argue that predominant feminist conceptions of gendered violence have fixed women as perpetual victims to be protected and rescued by state and law, affirming the inscription of male superiority and female inferiority. For Brown, it is crucial that feminist politics not permit the displacement of radical democratic forms of resistance with state and legal protection (Brown, 1995:169). For Marcus, the answer is to abandon the existing feminist 'script' of victimisation, and re-write it so as to articulate, and enable, women's agency and resistance, including their violent resistance to any attack (1992:386;395). In response to both, Mardorossian claims that their critique of victim subjectivity itself enacts a kind of victim blaming, and supports the traditionalist and reactionary parties who are invested in status quo binary sex and gender hierarchy (Mardorossian, 2002:749-50). For Mardorossian, feminist political stretching the concept of violence to incorporate hitherto normal, unnoticeable actions and interactions has, among other things, achieved the everyday consciousness of the wrong of violence against women - by governments, by individuals. Far from affirming women's victimisation, this consciousness has generated new principles and tactics of political response. Where a routine enactment of gender domination was a source and occasion of powerlessness or individual frustration, it has now become (potentially at least) 
the occasion for a shared, public, discourse of political protest and action (Mardorossian, 2002:764-5).

This debate is indicative of the range of concerns - generalisation, essentialisation, and victimisation - that have time and again attended feminist engagements with the question of gendered violence and its politics. Both Marcus and Brown are critical of what they see as feminist essentialism, whereas Mardorossian defends the focus on women’s experience as strategically crucial. They disagree with each other about the importance of structural and agentic factors in the explanation of gendered violence. Brown, in particular, is concerned that the generalisation of violence to all aspects of women's life and experience closes down the possibility of agency, threatening to push the question of gendered violence back into the naturalising frame that feminist arguments contested. Further, all three explicitly or implicitly assert a distinction between 'good' and 'bad' violence. For Marcus women's violence in selfdefence is good; for both Brown and Mardorossian, the violence of the state is problematic in contrast to popular, radical democratic protest. In the following section, we examine how similar conceptual and normative tensions have attended the feminist inspired mainstreaming of gendered violence onto the international policy agenda.

\section{Putting VAW and SGBV on the International Political Agenda}

The notion of violence against women as a violation of human rights was adverted to during the United Nations' (UN) third World Conference on Women, Nairobi 1985, at the end of the UN's decade for women (UN, 1985). This was undoubtedly due to the pressure from feminist activists involved nationally in such political campaigns and organisations as rape crisis telephone lines, reclaim the night marches, battered women's refuges, and woman-focussed economic and social development projects. However, at that point it was only 'an aside' 
(Kelly, 2005:478). Further significant breakthroughs, driven by feminist activism, occurred in the 1990s, after the 1993 Vienna Conference on Human Rights and the 1996 UN Women’s Conference in Beijing, after which VAW became increasingly acknowledged and framed as a human rights violation and a national and international policy priority (Htun and Weldon, 2012:555). In the same period, the rising profile of feminist activism around violence was reinforced by feminist attention to gendered violence in the context of war, wartime sexual violence in particular. This led to the mainstreaming of gender onto the international peace and security agenda and increased international government agencies’ (IGO) and international non-government agencies' (INGO) attention to the idea of sexual violence as a weapon of war (Pratt and Richter-Devroe, 2011; Kelly, 2015).

The UN Convention on the Elimination of All Forms of Discrimination Against Women (CEDAW) (UN 1981) had been adopted in 1979, and was followed over the decades by more specific resolutions (UN, 1992, 1993a, 2000, 2008, 2013). As Htun and Weldon explain, feminist activism, and feminist understandings of VAW were crucial to making the question of violence central to this agenda (2012; see also Kelly, 2005). They note that because 'VAW requires challenging male privilege in sexual matters and social norms of male domination more generally', it could not have been generated as a policy priority from within the established transnational policy community (2012:553). They also point, however, to the ways that once an issue is on the policy agenda and enshrined in agreements, protocols and regulations, the latter exert independent effects, and the direct influence of activist movements on the nature and shape of the agenda declines (564). The period in which VAW became a focus of international policy practice saw numerous reviews, reports and analyses by international agencies and authorities. ${ }^{2}$ In this corpus of documents, we can trace a

\footnotetext{
${ }^{2}$ Our corpus of documents includes: UN High Commission for Refugees (UN, 2003); Amnesty International (2004); WHO (2005); UN (2006); EU (2010); WHO (2010); WHO and London School of Hygiene and Tropical Medicine [LSHTM] (2010); Council of Europe
} 
variety of contentions concerning the concept of VAW that developed as part and parcel of its mainstreaming onto the international policy agenda. Some of these contestations are to do with the particular sorts of feminist insight that were most influential at the agenda's inception, while some are to do with more technical debates over how VAW is to be identified and measured as a condition of its being effectively counteracted.

We begin by examining some of the tensions that emerge within the discourse of the policy documents. A key claim of the VAW agenda, reflecting decades of feminist work on violence, is that VAW is gender based - the function and point is to assert and reinforce a two sex, binary gender system as compulsory and imperative. We see, though, that from an early stage the documents are concerned that this focus on binary sex and gender should not eclipse concern with the broader category of SGBV, encompassing for instance homophobic violence and violence against trans and non-binary persons (Amnesty International, 2004:8). The documents acknowledge both that women are often perpetrators of gender based violence including female genital cutting and assertions of 'family honour' by violent means against family members who violate norms of courtship and marriage, and that the background explanation of these forms of violence is the (violent) enforcement of a two sex, two gender hierarchical system.

A large body of empirical research supports the VAW framework taken up by international authorities (Dobash et al., 1992; UN, 1993b:4; Johnson and Ferraro, 2000; Dasgupta, 2002; Swan and Snow, 2002; Watts and Zimmermann, 2002: 1235; Dobash and Dobash, 2004; Wood et al., 2011:35). In turn, the international documents reinforce the findings of feminist research that binary gender norms are crucial to the understanding and

(2011); UN General Assembly (UN 2011); ICC Rome Statute (2011); EU (2012,2014); European Institute for Gender Equality [EIGE] (2015); UN Development Programme (UN, 2015b); UN (2015a); Council of Europe (2016). 
addressing of VAW and all other forms of SGBV (WHO and LSHTM, 2010: 29; Ricardo et al., 2011: 13-14; Milnes et al., 2015: S3.2.3.3; Barter et al., 2009). The presence of gender norms as a critical factor in the aetiology of violence against women means that ending it must, among other strategies, attempt to denormalise such standards of gender. UN Security Council and UNHCR resolutions and declarations (UN, 1992, 1993b, 2000, 2013), and subsequent recommendations and projects to end VAW and SGBV, involve addressing the investment that women as well as men have in the status quo, through various kinds of economic, legal and cultural reform, thereby loosening the hold of the binary gender system on lived lives (UN, 2006:159; UN 2011:21-22; EU 2014).

The policy documents also share the theme that explanation of patterns and incidence of VAW and SGBV must advert to causal and predispositionary factors at multiple levels: from the individual level of psychology, through social and economic institutions, and to the level of cultures and religions and their purveyance of norms, beliefs, myths and worldviews. Many of these mechanisms operate by way of justification, legitimation, and in general making sense of patterns of interaction between the agents and recipients of violence, by normalisation. Multi-level and ecological approaches emphasise context or environment, the interplay between micro, meso and macro level variables and factors, and embedded levels of causality (Heise,1998; WHO and LSHTM 2010:19; Heise,2011). They call for a multiple sector (economy, law, non-governmental organisations, government, education, health) approach (UN, 1993b, 2006: 13-14; 2011). The European Union Justice and Home Affairs Council identifies domestic violence as a cause of inequality, while inequality in turn exacerbates or causes violence (EU, 2014). They call for multi-level actions and measures against violence - by which levels they mean state, society, local, and inter-state strategies and agencies (3-6). The earlier Amnesty International report highlights the wide range of forms of violence, and of contexts or environments that are significant for the explanation of 
incidence and patterns, including economic exploitation, militarisation and conflict, and criminality including sexual exploitation and trafficking (Amnesty International, 2004). Again, there is the call for concerted action, between state and non-state institutions and sectors, as, in particular, criminal justice solutions are limited in their reach or efficacy (56; see also UN, 1993b:5). In this institution focussed, international effort, a body of ideas and projects focussed on the melioration and eventual elimination of VAW and SGBV are articulated and practiced. The first principle is that SGBV is continuous with forms of violence against 'women and girls'. Second, levels (personal, interpersonal, social, cultural, national, global) interact both in explanation and in action for change. Third, multiple mediating institutions - kinship, policing, military force, law, medicine, and so on - are important both in explanation of the status quo and as sites of action for change.

The feminist theory that underpins this multi-level and continual analysis builds on political and phenomenological insights discussed in the previous section. In particular, it reflects the idea that women's standpoint matters epistemologically, methodologically, and empirically (Smith, 1987/1974; Harding,(ed) 1987; Hartsock, 1987; Mackinnon, 2006). The idea of women's standpoint has shaped the design of research into VAW and SGBV, where earlier criminological and sociological surveys elided it. It also supports the expansiveness both of conceptions of VAW and SGBV and of the range of factors needed to address them.

However, this incepting standpoint of 'women and girls' is politically and analytically contentious. In many settings, contention is over the very idea of challenging what is understood to be a rightful, or natural, or theologically ordained, order. But in the broadly liberal policy context from which this wave of feminist thinking and action has emerged, contention is over whether such male domination is an accurate characterisation of the distribution of power. The incepting category of violence against women was challenged and in some research programmes and political projects replaced - by the more symmetrical 
concepts of 'intimate partner violence', 'domestic violence', 'gender based violence' and the like, which are consistent with the idea that violence can originate from either side of an antagonistic opposition (Dobash and Dobash,1992). This brings a 'feminist standpoint' into antagonistic competition with both a 'male standpoint' and a 'gender neutral' one. More significant for the development of the VAW agenda have been questions about the dangers of conflating the categories of 'women and girls' with 'gender', and of identifying 'women and girls’ with a single epistemological standpoint (Shepherd, 2008; Pratt and Devroe, 2011). The Special Rapporteur on violence against women to the UN, in her 2011 report, focusses particularly on intra-gender differences between women. For her, it is critical that the UN get to grips with the way that women are positioned differently in their susceptibility to genderbased violence, because of material differences along the lines of sexuality, ethnicity, and class (UN, 2011:7-8). The documents see a continuum, then, between VAW and SGBV, but there is also a tendency for these categories to collapse back into each other, so that SGBV is read as VAW, or VAW in some sense encompasses SGBV.

There are also tensions within the documents between more and less expansive understandings of the meaning of violence. Following the pathway of feminist analysis, insisting on multi-level and continual analysis of violence, the international agencies endorse an extended conceptualisation of violence, beyond the core physicalist case. Concepts of indirect in addition to direct violence; structural violence as well as agential; psychological, emotional, economic, epistemic and symbolic in addition to physical - are endorsed and deployed in the reports and policy documents. However, the distinctions that the documents make between direct and indirect, and between direct and structural, violences, are unclear and unstable (UN, 2011: SS30,31; EIGE 2015).

Direct and agent centred violence is certainly taken as centrally significant, given statistics of rape, battering, murder and other crimes in the purview of, for instance, the EU 
(EU, 2014). This, first, kind of violence includes and analytically differentiates: an actor or agent, the perpetrator; an action, the violence; and a recipient, the sufferer or victim. If we pick out the location of the violence using bold type, and set this out formally, we can represent it as: 1. Perpetrator, action, recipient. Notably, though, the European Institute for Gender Equality expands the analysis to incorporate sexual, psychological, and economic violence in addition to physical violence (EIGE, 2015:3). The action, in physical violence, is a blow, strike, stab, push. In psychological violence it can be an intimidating threat, a jibe, a shout rather than a blow. Economic violence can take the form of deprivation. In such cases we have departed from the physicalist connotation of velocity and force, but the recipient is still unable to evade injury or trauma, including the injury from the blow or its equivalent, and further trauma and ill effects as described in feminist theory (Kelly, 1988:147-155; Barnett, 2001 8-14; Lacey, 2010:670). Though expanded, this is still an action centred analysis, and it trades on, in the sense of being an extension of, the physicalist connotation of the concept violence.

The EIGE further argues that the category of direct sex gender violence must encompass the indirect violence inherent in the unequal power relations between men and women. In this second kind of violence focus is shifted from the action, to the context of relationships that permit, enjoin, or legitimate the action. The 'norms, attitudes and stereotypes around gender in general and violence against women in particular' which are 'engaged in the production and reproduction of attitudes which normalise violence against women ... contribute to and support direct forms of violence against women' (EIGE, 2017). The contextual relations are indirectly violent; the action is directly violent: 2. Context (indirect), perpetrator, action (direct), recipient.

The international agencies have tended to emphasise that structure - distributions of resources and constraints, norms and traditions - is indirectly related to actions like a 
husband's use of physical, emotional, or psychological violence, and the harms that result (including the reinforcement of the structure). They focus their attention on ways of altering the individual behaviour of men and women through different kinds of sanction and reform (UN, 2006:31-33,52,116,120). However, the documents also reflect the power of the alternative idea that structural inequality is, itself, a direct form of violence, acting directly on recipients to bring about injuries and trauma. This third kind of violence picks out consequences of the structural conditions, including the attitudes and conduct of audiences. In some cases, attitudes and conduct of relevant others might enjoin an act of violence from perpetrator to recipient - for instance, a father might order his son to beat his wife, effectively taking up the role of principal of the violence of which the son is agent. Equally, a general system of norms and values - such as the compulsory binary gender system - might permit violence. The explanatory weight, and the location of the violence, is as much with the structural context as with the perpetrator and his action: 3. Structure, principal, perpetrator, action, recipient. The concept of structural violence can be extended further to circumstances in which there is no violent action analogous to a blow, and away from an action focus altogether. In this distinct, fourth, kind of violence, wives are unable to evade injury, because of the force of the actions and inactions, the norms, the distributions of resources and constraints, that assail them (Galtung, 1975b:115). The injury of the inequality and disadvantage, the being forced into an 'inferior' subject identity, is equivalent to the injury from direct and indirect acts of violence. The effects can be measured by life expectancy or quality of life diminished. These effects are so significant, the trauma is such, that we must call the causes that bring them about 'violence': 4. Structure, principals, perpetrators, actions, recipients/injuries (EIGE, 2017).

These disputes about the salience of direct and indirect, structural and agential, violences have straightforward political significance. Walby and colleagues argue that only 
by identifying VAW with direct violence, in which there is an individuated perpetrator, an action, and a harmful effect on the recipient, can it (including who does what to whom, with what effects) be reliably measured, and therefore explained. This, in turn, is a prerequisite for identifying policies that will prevent the actions and eliminate the harm (Walby et al, 2017:5,35-42,58). They also insist that violation of rights has to be present. If measures against perpetrators are to be possible, and legitimate, their actions must fall into the category of the 'illegal' or 'criminal' under human rights, and ordinary criminal, law. Of course, this requires legal political effort to ensure that legislation appropriately reflects the normatively criminal nature of these forms of violence. Importantly, without comparability in modes of collecting data about sex gender violence across different contexts, we do not have a sound starting point for identifying what institutional solutions do or do not work. The work of Walby et al points to the close connection between the analytical and the political. It also, however, highlights the politics inherent in the shift from VAW as a subject of political mobilisation to VAW as a site of technical knowledge (Engle Merry, 2016: 45).

Engle Merry identifies four approaches in her account of UN debates over the production of 'indicators' and guidelines for data collection through which VAW could be measured: UNSC (UN Security Council); gender equality; human rights; and criminal justice. On her ethnographic account: ‘- these four approaches display significant cultural and interpretive differences in the way they conceive of, categorize, and count violence against women. They hold different underlying social theories about violence against women, but these theories are rarely made explicit' (2016: 45). She traces the political as well as analytical stakes in highly technical discussions over how to gather data and measure VAW. Here we see very clearly contestation over the definitions of VAW, which have direct implications for how it is to be addressed, and, less explicitly, normative contestation over what kinds of violence are acceptable from a feminist point of view, in particular when it 
comes to the violence of the state. The 'gender equality' approach, which most directly reflected feminist civil society activism, pushed to establish indicators that reflected a broad definition of violence: ‘as socially embedded in structures of inequality and patriarchy’ (64-5; 86). In contrast, the UNSC pushed for the identification of VAW with individual, physical acts of violence as being the most clearly measurable, but also as detaching VAW from tricky issues of state violence and of cultural context (78; 107). 'Human rights' and 'criminal justice' approaches were positioned between these two extremes. In the case of 'human rights', however, in keeping with the broader international human rights regime, this approach preferred simpler, non-contextual definitions - less integrated with background structures and processes (95). As for 'criminal justice', in wanting to harmonise counting of VAW with other crime data, it was 'much less concerned with measuring gender inequality or non-criminal actions such as abusive or controlling behaviour within relationships’ (100).

\section{Feminist Politics and Conceptualising Violence}

At the beginning of this paper we noted that a major achievement of feminism has been to identify gendered violence as fundamentally political. However, as our discussion of theoretical and practical work on VAW and SGBV demonstrates, the feminist challenge to traditional ways of thinking about gendered violence does not remove us from political contestation when it comes to conceptualising political violence from a feminist point of view. As we have seen, the analysis articulated by the global agencies is premised on the continua of violence, and on a validated theory of common causation, which in turn is premised on the phenomenology of women's lives (eg WHO, 2005, 2010; WHO \& LSHTM, 2010). As Kelly puts it, 'A vital part of feminist work around sexual violence has been to provide names that describe women's experience' (Kelly, 1988:139). This framework is 
central to the dominant theoretical feminist discourses on violence in the 1980s and 1990s, and to what Engle Merry terms the 'gender equality' approach to measuring VAW in twenty first century attempts to operationalise feminist insights in international public research and policy. It has, however been challenged from rival directions, with rival implications for what counts as gendered violence and how such violence should be countered.

We suggest distinguishing between challenges to the 'gender equality' approach that depoliticise the concept of VAW/SGBV, and those that seek to politicise it in an alternative way. Each of these challenges offers a different understanding of what counts as violence, how it should be contested, and, implicit in this, how we can distinguish between 'good' and 'bad' violence. Depoliticising arguments rest on the most narrow conceptions of VAW/ SGBV - they identify it solely with individual acts of direct physical violence for which a perpetrator and a victim can be clearly identified. Such definitions are depoliticising because they reverse the process through which feminists originally named VAW as political violence. The closest example of this we have seen, unsurprisingly, is in the UNSC approach, which has a vested interest in defusing the fundamental challenge that feminist insights into gendered violence pose to existing patriarchal hierarchies and relations. Here we return to moralising and criminalising discourses in which VAW becomes a matter of individual wrong, excess or pathology, as opposed to a systematic expression and reinforcement of an unequal, compulsory, binary gender order. On this account, VAW is defined as physical assaults on women, and must be countered by the same kind of ideological and legal mechanisms that societies use to constrain violence in general. State violence, exercised through law and encouraged through a variety of carrots and sticks at the international level, is 'good'. The violence of husbands who beat their wives is 'bad'. The UNSC position confirms Htun and Weldon's claim that as an issue moves from the arena of civil society 
mobilisation to the realm of international public policy-making, the influence of the inspiring social movement on the policy agenda is likely to decline (Htun and Weldon, 2012: 564-5).

Few feminists would endorse the UNSC position. However, there are clearly ways in which the criminal justice and the human rights positions, although more expansive in their accounts of gendered violence, also individualise the meaning of VAW/SGBV and are grounded in the languages of morality and legality. Here we can see clearly the political dilemmas involved in holding onto a feminist perspective while mainstreaming feminist concerns. Walby, who combines criminal justice and human rights perspectives, insists on a narrow agent violence concept, which is operationalisable in cross-national research, and can be used to put pressure on governmental, police, and judicial authorities. The aim is to punish criminal violence and to turn education, health, welfare and cultural institutions to the achievement of equity, in accordance with the visions and programmes of the UN, the EU, the WHO, and other global agencies, and in pursuit of some of the aims of feminist and gender justice. Walby accepts that harms of violence and other forms of harm are connected, as feminist theorists have always insisted. But her point is that you cannot deploy an expansive conceptualisation of violence politically to build the kind of transnational instruments she argues are necessary for violence and those other harms to be ameliorated. Nevertheless, Walby's separation of VAW and SGBV is more than a purely instrumental move. She endorses the individualisation of these phenomena analytically, not only in the sense that they should be defined as individual actions with a perpetrator and a victim, but also in the sense that they are events open to specific explanation by other factors such as the broader enforced pattern of binary gender structure and ideology. She also endorses a clear normative distinction between the violence of the state, which is key to countering gendered harms, and the violence of non-state individuals, who are the objects of punishment. The 
victims of violence figure largely in their role as victims, exerting limited agency in the overarching juridical-legal context.

The UNSC approach tries to take VAW/SGBV out of politics. Walby and her colleagues seek to attach the VAW/SGBV agenda to a specific kind of feminist state and inter-state politics. Both positions contest and constrain the politics of the gender equality position. At the other extreme, however, all of these positions, including that of gender equality, are in turn contested by feminist critics unhappy about what they see as the essentialism, statism, and denial of women's agency embedded in the VAW/SGBV agenda (Davies and True, 2015; Engle Merry, 2016; Pratt and Richter-Devroe, 2011; True, 2012; Shepherd, 2008). Critics of essentialism point to the persistent conflation of 'women' and 'gender', and to the treatment of 'women' as an undifferentiated category in the domain of international public policy. This leads, they argue, to lack of attention to issues of different kinds of hierarchies of power and their intersections, including diverse gender hierarchies. This is in turn links to neglect of global structural violence, to the rendering of feminised subjects as objects rather than agents of change, and, potentially, to the uncritical endorsement of the violence of states. In general, these positions support the feminist phenomenological and expansive tradition for thinking about gendered violence, but oppose decontextualised, over-generalised, understandings of gendered experience, and oppose the operationalisation of VAW by way of the extension of the policing and juridical powers of state and inter-state agents. They are wary of the detachment of analysis of VAW/ SGBV not only from patriarchal structures, but also from global structures of racialisation and political economy (True, 2012). In particular, they are concerned with the ways in which the VAW/ SGBV agenda may itself become complicit in gendered violence on a massive scale: 'A mission to eradicate gender-based violence and "empower” women may end up being 
justification for foreign (military) intervention thereby maintaining global hierarchies’ (Pratt and Richter-Devroe, 2011:496).

\section{Conclusion}

Defenders of unequal sex and gender relations justify sex gender violence as natural, or as traditional, or deny that it is violence at all - it is a joke, or an expression of love, or an accident. That is, they draw a boundary around the concept violence, for political purposes. (Wittgenstein 1958: S.69). Women fighting back, and feminist activists campaigning for change, draw conceptual boundaries designed to have specific political effects. The critics of the feminist activists whose understandings of SGBV have been adopted by global authorities like the UN challenge these boundaries, arguing that feminist political construction of 'women’ unjustly excludes the possibility of a range of alternative identities and agencies.

We have discussed several distinct feminist positions in relation to how violence is conceptualised, how boundaries are drawn. The analyses of structural, symbolic and epistemic violences that harm and traumatise persons based on their sexual and gender identities, and which enact and enforce the two sex two gender hierarchy, according to their proponents, capture both how violence is done and its effects. Walby and her colleagues dissent from broadening the scope of sex gender violence beyond a physicalist, action centred analysis, because the displacement of perpetration and action undermines feminist political efforts to end gendered violence: 'Blocking the separate identification of violence from other aspects of gender inequality prevents any effective analysis of the relationship between gender inequality and violence' (Walby, 2015:35). In response to this, critics object that analysis of violence in terms of individual acts has had the effect of confirming and entrenching, rather than challenging, women's victimisation. It blocks the capacity to contest 
the relations of power that render gendered violence a political, rather than a natural, moral, or criminal issue. Furthermore, it reinforces dependence on the violence of authorities national police forces, government legislators, judicial punishers - to act against violence, undermines women's grassroots agency, and marginalises the intersection of gender with other oppressive structures embedded in the politics of states and of inter-state organisations.

Our aim has been to insist on the political force of these conceptual and theoretical disputes. Conceptualisations of violence have persuasive force in political discourse. They have power, in particular, because of the rhetorical resonances of 'violence' as a term. It is the work that conceptualisations of violence do, as much as the reality of oppression and injury that they reveal and articulate, that underlies ongoing feminist contestation about the meaning and scope of gendered violence. This means that the persuasive force of such conceptualisations for an audience will depend very largely on their implications for concrete political strategy. In turn, commitments regarding the best political strategies for contesting gendered violence will condition conceptual commitments. Being alert to the politics inherent in particular definitions and operationalisations of terms such as VAW and SGBV means being attentive to two sorts of question. First, to what extent does a way of naming violence take politics out of the discussion? Where gendered violence is reduced to the individual acts of 'bad' perpetrators, then the feminist politics that put violence on the political agenda in the first place is lost. Second, what kind of politics does a way of naming violence leave on the feminist agenda? Is it one that essentialises the positioning of women or other feminised subjects in relation to gendered violence? Or one that is committed to vernacularizing the meaning of gendered violence for a range of particular subjects in particular contexts? In particular, what kind of line between 'good' and 'bad' violence does it draw? Raising these questions is not to denigrate the amazing success of feminist theorists and civil society activists in getting gendered violence onto national and international political agendas as 
never before. Rather, it is to argue for continual awareness of the political contestations at the heart of feminist namings of violence, and to point to the dangers of assuming that the argument about what counts, in the categories of gendered violence, could be settled.

\section{References}

Amnesty International (2004) 'It's in our hands: Stop Violence Against Women'. London: Amnesty International.

Barnett, Ola W. (2001) 'Why Battered Women do not Leave Part 2: External Inhibiting factors - Social Support, and Internal Inhibiting Factors', Trauma, Violence and Abuse, 2 (1), 3-35.

Barter, Christine, et al. (2009). 'Partner exploitation and violence in teenage intimate relationships'. London: National Society for the Prevention of Cruelty to Children.

Bayard de Volo, Lorraine and Hall, Lynn K. (2015) '”I Wish All the Ladies Were Holes in the Road": the US Air force Academy and the Gendered Continuum of Violence'. Signs: journal of women, culture and society. 40 (4): 865-889.

Bourdieu, Pierre (2001 fp 1988) Masculine Domination, trans. Nice, Richard. Cambridge: Polity.

Bourdieu, Pierre and Jean-Claude Passeron (1990 fp French 1970) Reproduction in Education, Society and Culture, trans. Wacquant, Loic J. D. London: Sage Publications.

Brison, Susan (1998) "Surviving Sexual Violence: a philosophical perspective”, in French, Teays \&Purdy (eds) (1998): 11-26.

Brown, Wendy (1995) States of Injury: power and freedom in late modernity. Princeton: Princeton University Press.

Brownmiller, Susan (1975) Against Our Will: men, women and rape. New York: Simon and Schuster.

Brunner, Claudia (2007) 'Occidentalism Meets the Female Suicide Bomber: a critical reflection on recent terrorism debates; a review essay', Signs: Journal of Women Culture and Society 32 (4): 957-971.

Bryson, Valerie (1992) Feminist Political Theory: an introduction, ed. Campling, Jo, Women in Society. Basingstoke: Macmillan. 
--- (1999) Feminist Debates: issues of theory and political practice. Basingstoke: Macmillan.

Council of Europe (2011) 'Convention on Preventing and Combating Violence Against Women and Domestic Violence (Istanbul Convention)'. Brussels: Council of Europe.

Council of Europe (2016). 'Ensuring Data Collection and Research on Violence Against Women and Domestic Violence: Article 11 of the Istanbul Convention - a collection of papers on the Council of Europe Convention on preventing and combatting violence against women and domestic violence'. Prepared by Sylvia Walby, Brussels: Council of Europe.

Dasgupta, Shamita Das (2002) 'A Framework for Understanding Women's Use of Nonlethal Violence in Intimate Heterosexual Relationships', Violence Against Women, 8, 13641389.

Davies, Miranda ed. (1994) Women and Violence: Realities and Responses Worldwide London: Zed Books.

Davies, Sarah E. and True, Jacqui (2015) 'Reframing conflict-related and gender-based violence: bringing gender analysis back in’, Security Dialogue 46 (6): 495-512.

Dobash, R. Emerson and Dobash, Russell P. (eds) (1998) Rethinking Violence Against Women, Thousand Oaks CA.: Sage Publications.

Dobash, Russell P. and R.Emerson Dobash. 2004. 'Women's Violence to Men in Intimate Relationships: working on a puzzle', British Journal of Criminology, 44, 324-349.

Dobash, Russell P., et al. (1992) 'The Myth of Sexual Symmetry in Marital Violence', Social Problems, 39 (1), 71-91.

Dotson, Kristie (2011) ‘Tracking Epistemic Violence, Tracking Practices of Silencing’ Hypatia 26 (2): 236-257.

Engle Merry, Sally (2016) The Seductions of Quantification: measuring human rights, gender violence and sex trafficking. Chicago: Chicago University Press.

European Institute for Gender Equality (2015) 'Strategic Framework on Violence Against Women 2015-18'. Brussels: EIGE.

--- (2017) 'Gender-based violence', <http://eige.europa.eu/gender-based-violence/whatgender-based-violence/forms-gender-based-violence>, accessed May 2017.

European Union (2010) 'Council Conclusions on the Eradication of Violence Against Women in the European Union'. Brussels: Justice and Home Affairs Council/Consiglium Europa Press Office.

--- (2012) 'Council Conclusions on Combatting Violence Against Women and the Provision of Support Services for Victims of Domestic Violence'. Brussels: Justice and Home Affairs Council/Consiglium Europa Press Office. 
--- (2014) 'Council Conclusions: 'Preventing and combating all forms of violence against women and girls, including female genital mutilation". Brussels: Justice and Home Affairs Council/Consiglium Europa Press Office.

French, Stanley G., Teays, Wanda \& Purdy, Laura M. (eds) (1998) Violence Against Women: philosophical perspectives, Ithaca and London: Cornell University Press.

Galtung, Johan (1975a) 'Structural and Direct Violence: a note on operationalisation', Peace: Research, Education, Action - essays in peace research Volume 1. 135-139. Copenhagen: Christian Ejlers.

--- (1975b) Essays in Peace Research. Copenhagen: Ejlers.

Harding, Sandra ed. (1987) Feminism and Methodology: social science issues Milton Keynes: Open University Press.

Hartsock NCM. (1987 fp 1983) The Feminist Standpoint: Developing the ground for a specifically feminist historical materialism. In: Harding S (ed) Feminism and Methodology. Milton Keynes: Open University Press.

Heise, Lori (1998) 'Violence against Women: an integrated, ecological framework', Violence Against Women, 4 (3), 262-290.

--- (2011) 'What works to prevent partner violence? an evidence overview'. London: STRIVE Research Consortium, London School of Hygiene and Tropical Medicine.

Hudson, Valerie M., Ballif-Spanvill, Bonnie, Caprioli, Mary and Emmett, Chad F. (2010) Sex and World Peace. New York: Columbia University Press.

Htun, Mala and Weldon, S. Laurel (2012) 'The Civic Origins of Progressive Policy Change: combating violence against women in global perspective, 1975-2005’, American Political Science Review, 106 (3): 548-569.

Johnson, Michael P. and Kathleen J. Ferraro (2000) 'Research on Domestic Violence in the 1990s: Making Distinctions', Journal of Marriage and the Family, 62, 948-963.

International Criminal Court (2011 fp2002) 'Rome Statute of the International Criminal Court’. The Hague: International Criminal Court.

Kelly, Liz (1988) Surviving Sexual Violence. Cambridge: Polity Press.

--- (2005) 'Inside Outsiders: Mainstreaming Violence Against Women into Human Rights Discourse and Practice', International Feminist Journal of Politics, 7 (4), 471-495.

Lacey, Krim K (2010) 'When is it enough for me to leave? Black and Hispanic women's response to violent relationships', Journal of Family Violence, 25 (7), 669-677.

Lundgren, Eva (1998) 'The Hand that Strikes and Comforts: Gender construction and the tension between body and symbol', in Dobash, R.Emerson and Russell P. Dobash 
(eds.), Rethinking Violence Against Women. 169-198. Thousand Oaks Ca.: Sage Publications Inc.

Mackinnon, Catharine (2006) Are Women Human: and other international dialogues. Cambridge MA: Harvard University Press.

Marcus, Sharon (1992) 'Fighting Bodies, Fighting Words: a theory and politics of rape prevention’. In Judith Butler and Joan W. Scott Eds. Feminists Theorize the Political. New York and London, Routledge: pp. 385-403.

Mardorossian, Carine M.( 2002) 'Towards a New Feminist Theory of Rape', Signs, 27 (3), 743-775.

Milnes, Kate, et al. (2015) 'Sexual Bullying in young people across five European countries: Research Report for the Addressing Sexual Bullying Across Europe (ASBAE) Project'. Brussels: ASBAE

Morgan, Karen and Suruchi Thapar Bjorkert (2006) "I'd rather you'd lay me on the floor and start kicking me': Understanding symbolic violence in everyday life', Women's Studies International Forum, 29, 441-452.

Pratt, Nicola and Richter-Devroe (2011) 'Critical Examining UNSCR 1325 on Women, Peace and Security’, International Feminist Journal of Politics, 13 (4): 489-503.

Ricardo, Christine, Marci Eads, and Gary Barker (2011) 'Engaging Boys and Young Men in the Prevention of Sexual Violence: a systematic and global review of evaluated interventions'. Pretoria SA: Sexual Violence Research Initiative and Promundo.

Shepherd, Laura (2008) 'Power and Authority in the Production of UNSCR 1325', International Studies Quarterly, 52 (2): 383-404.

Skjelsbæk, Inge (2003) 'Sexual Violence and War: Mapping out a Complex Relationship', European Journal of International relations, Vol. 7, No. 2. : 211-237.

Smith, Dorothy (1987 fp 1974) 'Women's perspective as a radical critique of sociology', in Harding, Sandra (ed.), Feminism and Methodology. Milton Keynes: Open University Press.

Spivak, Gayatry Chakravorty (1988) "Can the Subaltern Speak?". In Marxism and the Interpretation of Culture, edited by C. Nelson and L. Grossberg, 271-313. Basingstoke: Macmillan Education.

Swan, Suzanne C. and David L. Snow (2002) 'A Typology of Women's Use of Violence in Intimate Relationships', Violence Against Women, 8 (8), 286-319.

True, Jacqui (2012) The Political Economy of Violence Against Women Oxford: Oxford University Press.

United Nations (1981) Convention of the Elimination of All Forms of Discrimination against Women. New York: United Nations General Assembly. 
--- (1985) 'Report of the World Conference to Review and Appraise the Achievements of the United Nations Decade for Women: Equality, Development and Peace. Nairobi July 1985. New York: United Nations.

--- (1992) 'Convention on the Elimination of Discrimination Against Women: General Recommendation 19, on violence'. New York: United Nations.

--- (1993a) 'Declaration on the Elimination of Violence Against Women'. New York: UN General Assembly.

--- (1993b) 'Strategies for Confronting Domestic Violence: a resource manual'. in Centre for Social Development and Humanitarian Affairs (ed.). New York: United Nations.

--- (2000) Resolution 1325 (on women, armed conflict, security and peace). New York: United Nations Security Council

--- (2003) 'Sexual and gender based violence against refugees, returnees and internally displaced persons: Guidelines for prevention and response'. London: United Nations High Commission for Refugees.

--- (2006) 'Ending violence against women: From words to action'. New York: United Nations Study of the Secretary-General.

--- (2008) Resolution 1820 (on sexual violence during wars). New York: United Nations Security Council.

--- (2011) 'Report of the Special Rapporteur on violence against women, its causes and consequences. By Rashida Manjoo. New York: Human Rights Council.

--- (2013) Convention on the Elimination of All Forms of Discrimination Against Women: General Recommendation no.30 on women in conflict prevention, conflict and postconflict situations. New York: United Nations.

--- (2015a) Preventing Conflict, Transforming Justice, Securing the Peace: A Global Study on the Implementation of United Nations Security Council resolution 1325. By Radhika Coomaraswamy, New York: United Nations.

--- (2015b) 'Sustainable Development Goals'. New York: United Nations Development Programme United Nations High Commissioner for Refugees

Walby, Sylvia, et al. (2015) Stopping Rape: towards a comprehensive policy. Bristol: Policy Press.

Walby, Sylvia, et al. (2017) The Concept and Measurement of Violence against Women and Men. Bristol: Policy Press.

Watts, Charlotte H and Cathy Zimmermann (2002) 'Violence Against Women: Global Scope and Magnitude ', The Lancet, (359), 1232-1237. 
Wittgenstein, Ludwig (1958, 1st edn 1953) Philosophical Investigations (trans.

G.E.M.Anscombe) Oxford: Basil Blackwell.

Wood, Marsha, Christine Barter, and David Berridge (2011) 'Standing on my own two feet:

Disadvantaged teenagers, intimate partner violence and coercive control' .London:

National Society for the Prevention of Cruelty to Children.

World Health Organisation (2005) 'WHO Multi-Country Study on Women's Health and Domestic Violence Against Women'. Geneva: WHO.

--- (2010) 'Addressing violence against women and HIV/AIDS: what works?'. Geneva: World Health Organisation.

World Health Organisation and London School of Hygiene and Tropical Medicine (2010) 'Preventing intimate partner and sexual violence against women: taking action and generating evidence'. Geneva: WHO.

Zarkov, Dubravka (2001) 'The Body of the Other Man: Sexual Violence and the Construction of Masculinity, Sexuality and Ethnicity in the Croatian Media' in Moser, C. and Clark (eds) Victims, perpetrators or actors? Gender, Armed Conflict and Political Violence, London: Zed Books. 